Supporting Information

For

\title{
Synthetic Analogues of the Active Site of the A- cluster of Acetyl Coenzyme A Synthase/CO Dehydrogenase: Syntheses, Structures, and Reactions with CO
}

Todd C. Harrop, ${ }^{\text {a }}$ Marilyn M. Olmstead, ${ }^{\text {b }}$ and Pradip K. Mascharak ${ }^{* a}$ 


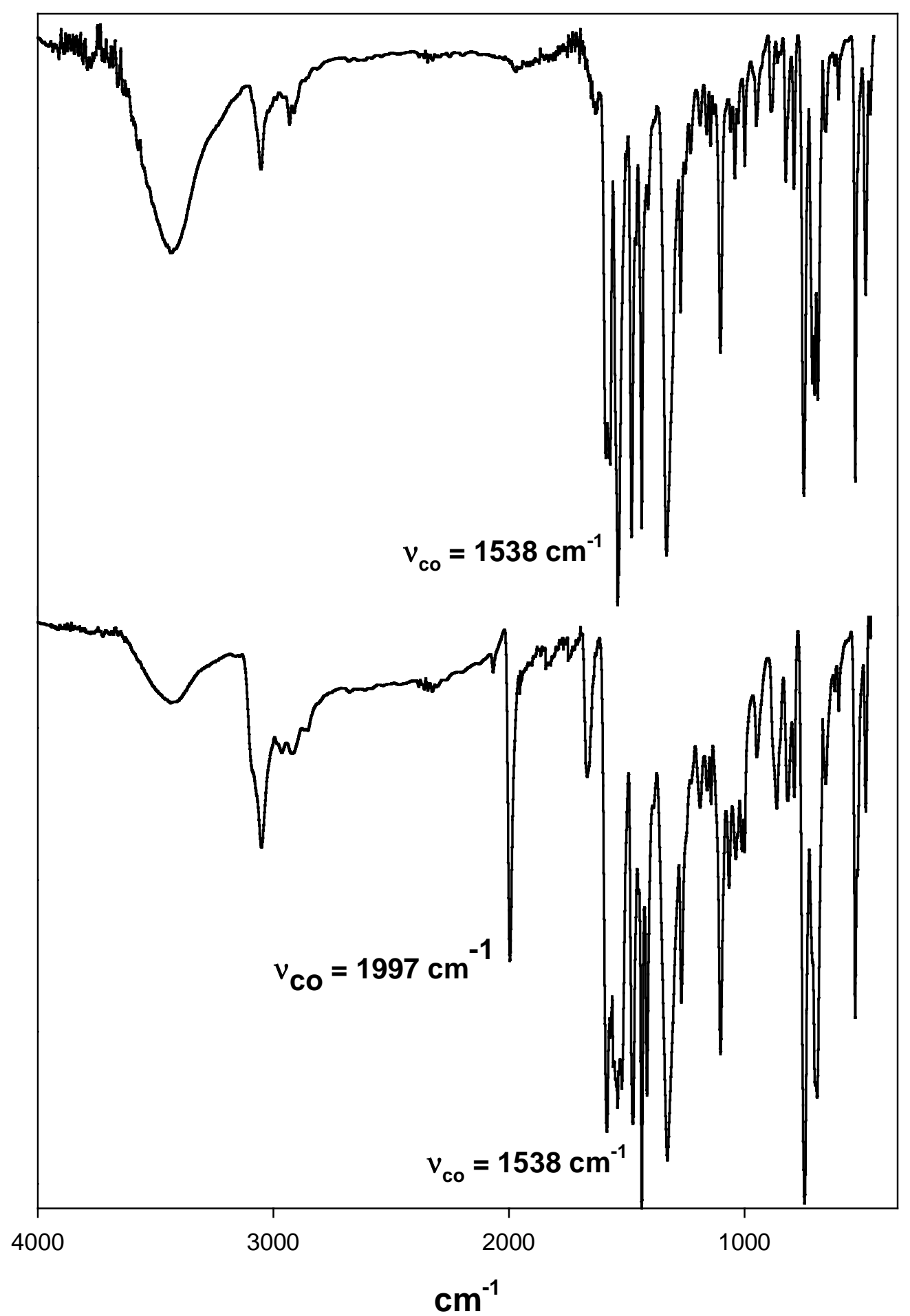

Figure S1. FTIR spectrum of [Ni(dppe)Ni(PhPepS)] (10, top panel) and $\left[\mathrm{Ni}^{\mathrm{I}}(\mathrm{dppe})(\mathrm{CO}) \mathrm{Ni}(\mathrm{PhPepS})\right]^{-}\left(\mathbf{1 0}_{\text {red }^{-}} \mathbf{C O}\right.$, bottom panel) in $\mathrm{KBr}$ matrix. 


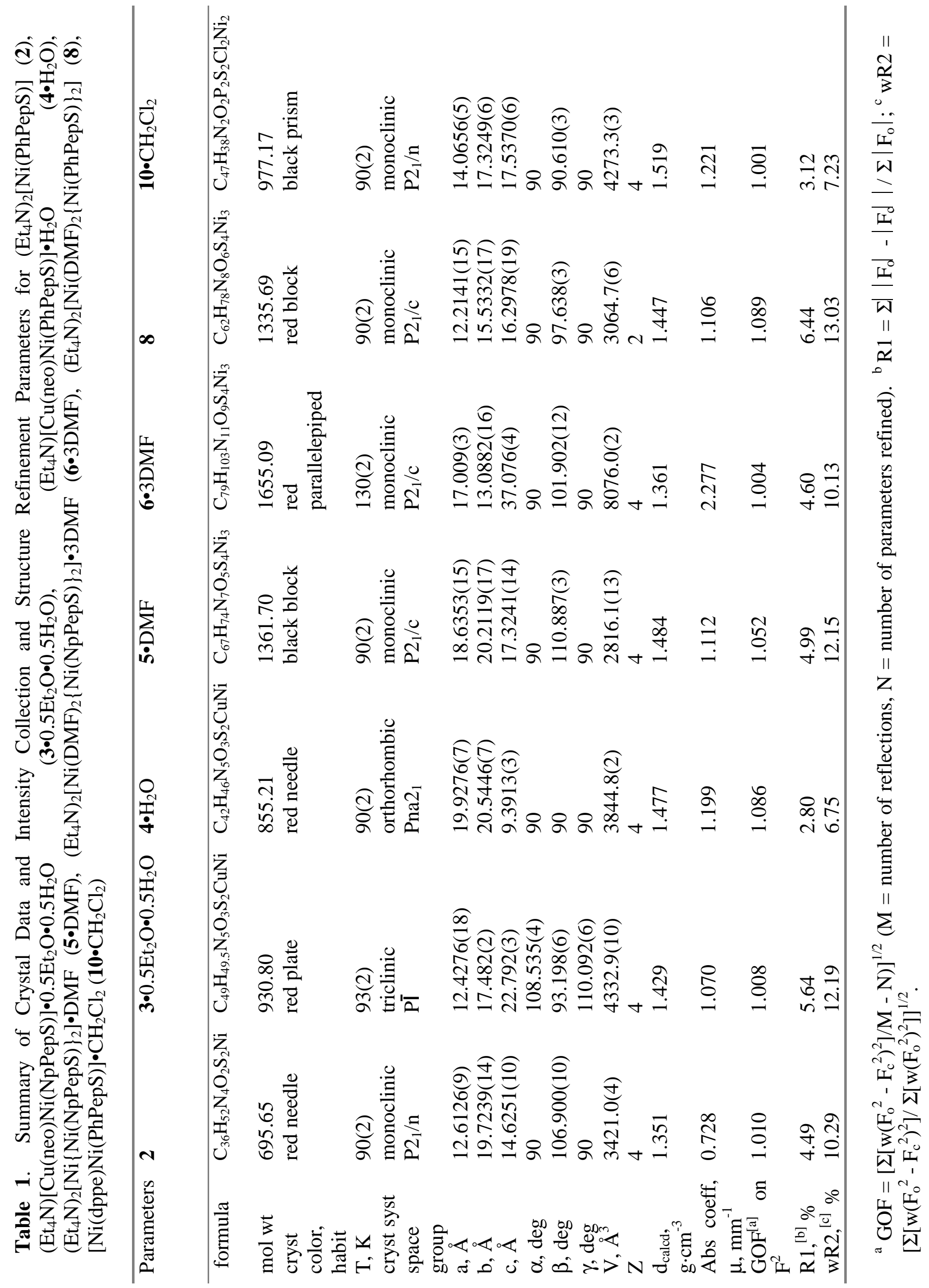




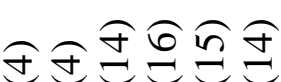

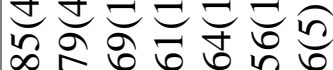

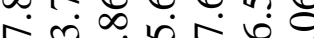

$=-\dot{2}=0$

तथ

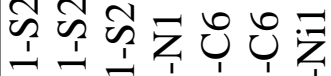

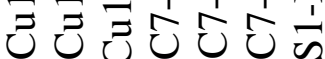

它古的宁市它

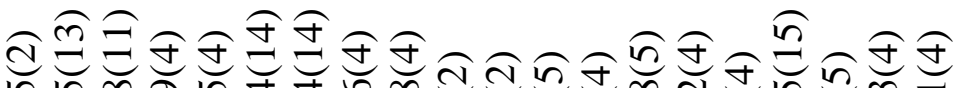
m

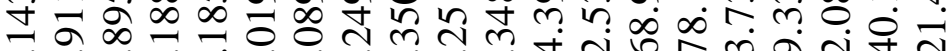

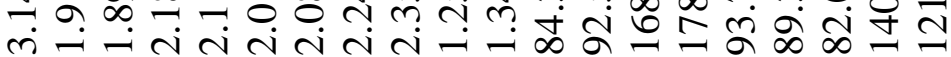

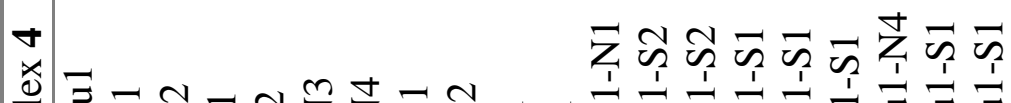

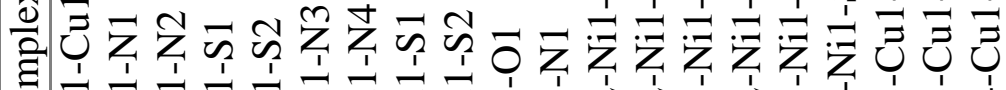

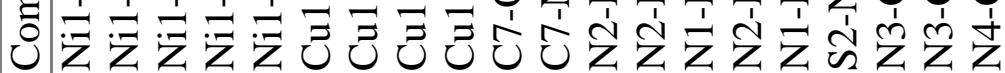

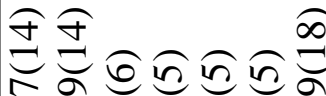

이의의

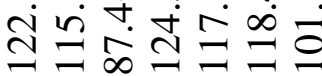

ㄷำ

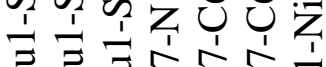

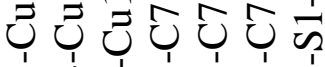

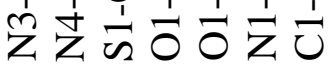

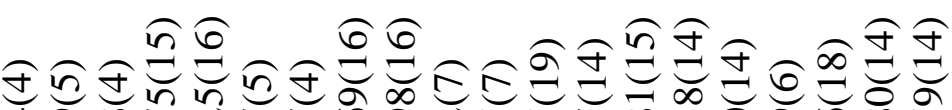

子。의

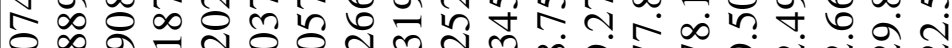
m.

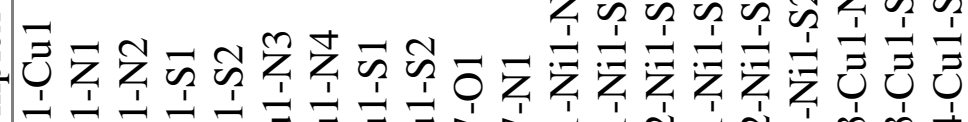

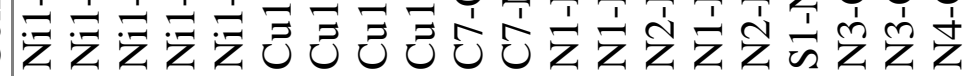

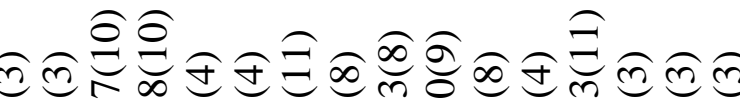

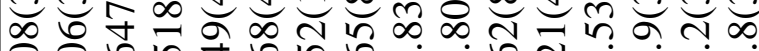

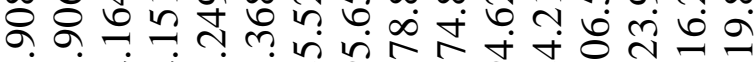
- 


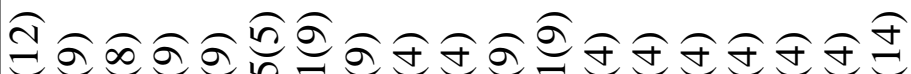

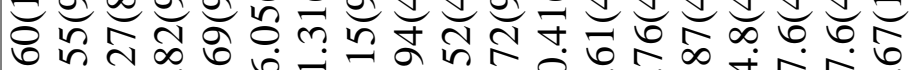

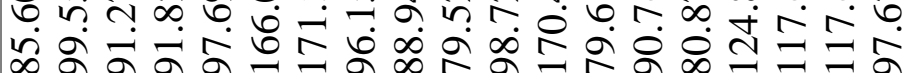

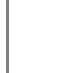

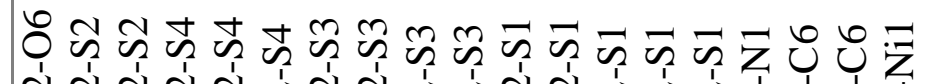

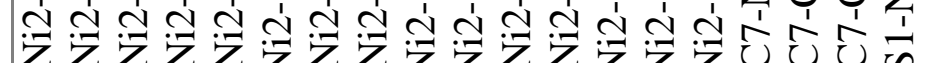

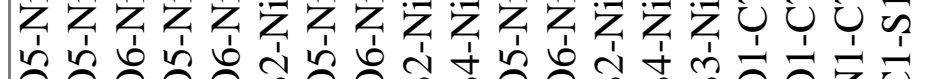

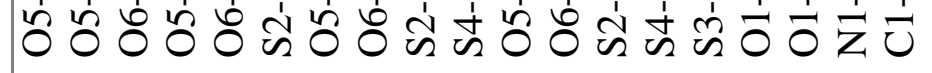

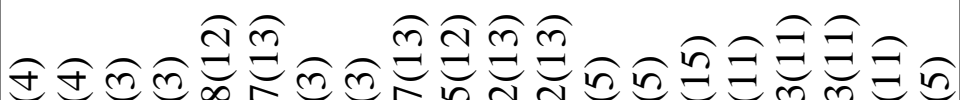
t

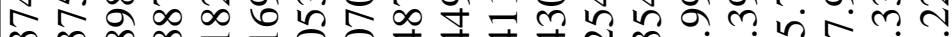
mं m

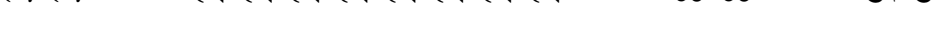

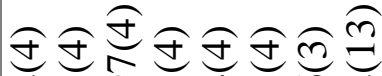

4.

n.

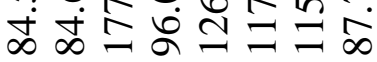

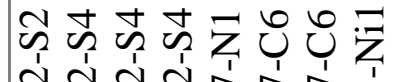

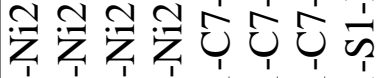

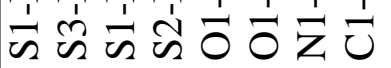

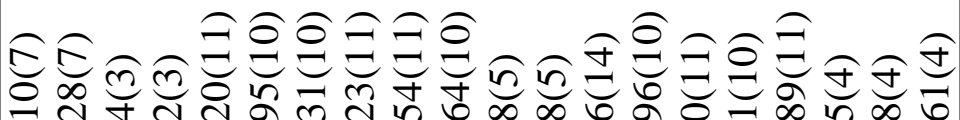
궁 त స

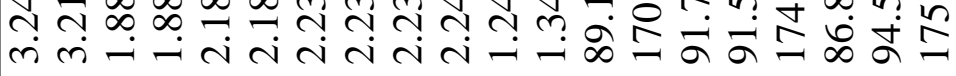




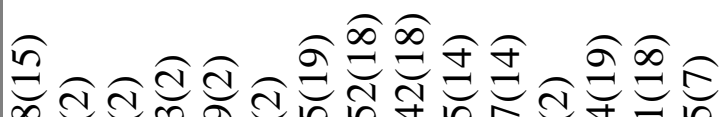

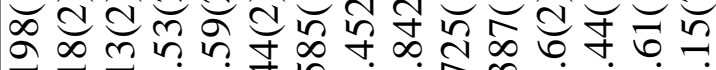

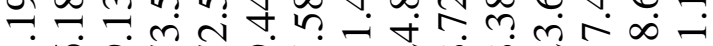

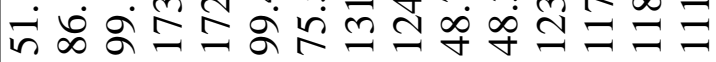

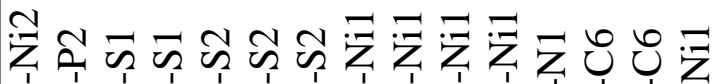

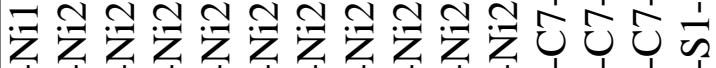

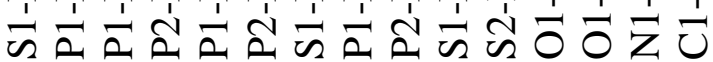

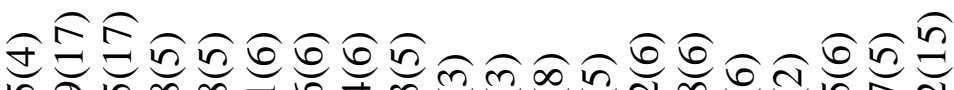

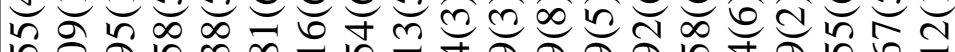

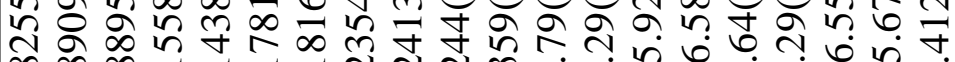

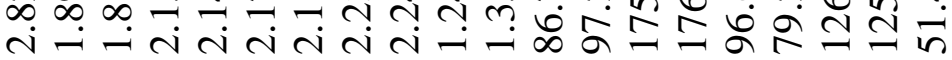

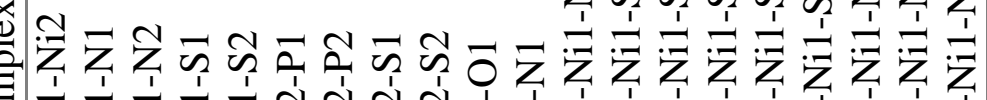

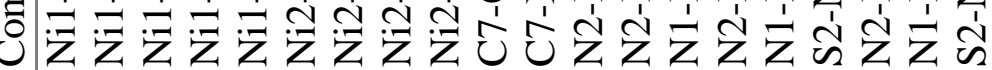

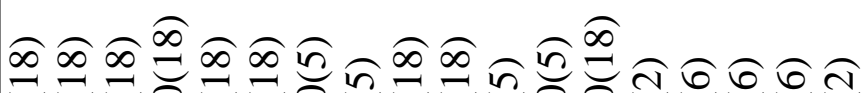

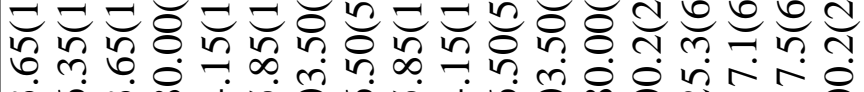
๙்

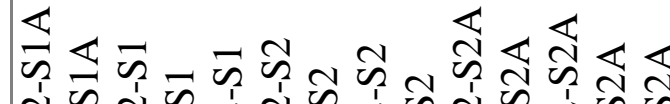

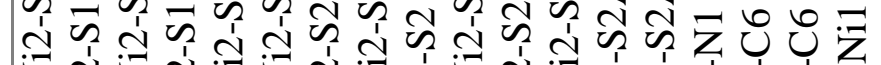

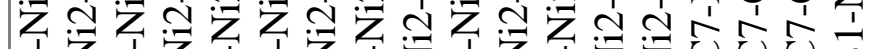

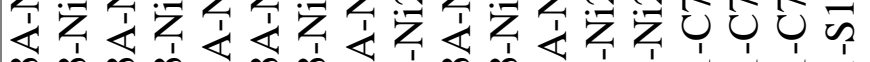

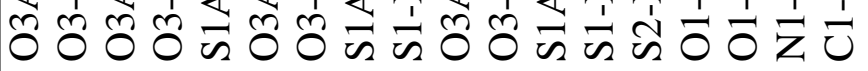

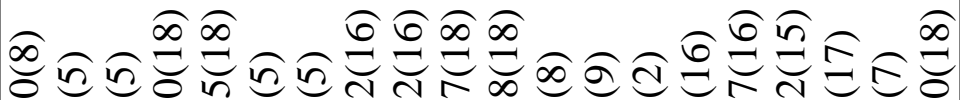

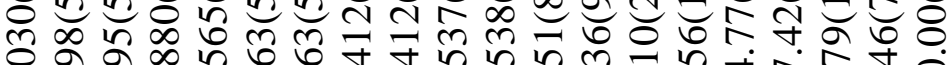

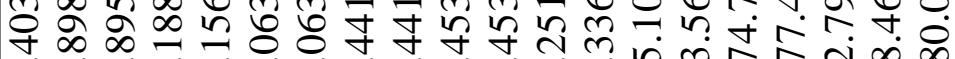
m-i i i i i i i i-i

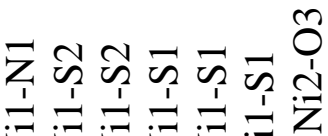

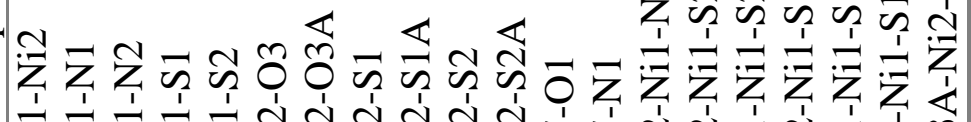

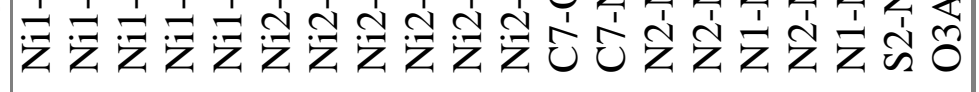


